\title{
A LITERATURA COMO CERIMÔNIA E ARTIFÍCIO: UMA TEORIA DA LEITURA A PARTIR DA OBRA DE GIORGIO MANGANELLI
}

\author{
Claudemir Francisco Alves*
}

\begin{abstract}
Resumo: Na obra do escritor italiano Giorgio Manganelli, autor, leitor e texto se desontologizam e se tornam componentes performativos, papéis pragmáticos que fazem, da literatura, um jogo de produção de sentidos contingentes. Privilegiando a leitura de um gênero textual manganelliano aqui designado como dispersão narrativa, essa peculiar teoria da leitura é analisada à luz da teoria formal da recepção, de Karlheinz Stierle, e da antropologia literária, de Wolfgang Iser.
\end{abstract}

Cerca de quarenta anos de trabalho como escritor, tradutor, ensaísta, jornalista, crítico de arte e de literatura fizeram de Giorgio Manganelli um personagem importante no panorama intelectual italiano da segunda metade do século XX. No entanto, é apenas a partir dos anos 1990 que uma relativa escassez de estudos sobre sua obra cede lugar a uma profusão de eventos e de trabalhos acadêmicos, em seu país e no exterior, ao mesmo tempo que suas obras são traduzidas para diversos idiomas (incluindo a edição brasileira de três delas ${ }^{1}$ ). Seus livros estão sendo reeditados

* Pontifícia Universidade Católica de Minas Gerais.

${ }^{1}$ São elas: Hilarotragoedia (Imago, 1993), Centúria (Iluminuras, 1995) e Pinóquio: um livro paralelo (Companhia das Letras, 2002). 
na Itália, e textos inéditos ou antes esparsamente publicados têm sido organizados e postos ao alcance do público.

Essa reapreciação de Manganelli, ao menos pelo meio acadêmico, contraria a expectativa de seus opositores, para os quais o projeto literário manganelliano, confinado num tratamento imanentista do texto e circunscrito a problemas específicos da literatura italiana do pós-guerra, estaria condenado a desaparecer com as contingências em meio às quais emergiu. Ao invés disso, as questões suscitadas pela produção crítica e literária manganelliana recentemente ganharam força, projetadas, agora, sobre o pano de fundo das discussões filosóficas e literárias pós-estruturalistas. Menos desfavorável nos últimos anos do que no início, a distinta recepção da obra de Manganelli parece decorrer tanto de mudanças conjunturais quanto de uma dinâmica nova que seu projeto literário assume à medida que vai se consolidando. Essa é uma razão para supor que o sistema conceitual elaborado por Manganelli pode suscitar questões válidas para os estudos de literatura contemporânea.

No cenário fortemente marcado pela naturalização neorealista do conhecimento e da comunicação, nos anos 1960, Manganelli encontra uma linha de fuga na assunção de que todo conhecimento é determinado pela linguagem. Afiliando-se a uma vasta tradição filosófica e literária, postula a realidade não como um dado pronto e acabado, mas como resultante da ação criativa da linguagem. Com isso, torna imanente a metafísica, fazendo-a deslizar para o espaço do jogo. A maneira peculiar como é agenciado esse pressuposto epistemológico, de modo a constituir uma teoria crítica e a se configurar num procedimento literário, singulariza Manganelli na literatura italiana.

\section{A CERIMÔNIA E O ARTIFÍCIO}

Embora a multiplicidade de gêneros que se entrecruzam na obra de Manganelli dificilmente possa ser reduzida a uma 
descrição sumária, pode-se dizer que, em geral, ocorre, em seus escritos, um meticuloso cancelamento de referências a uma realidade exterior àquela constituída pelo próprio texto. Esse procedimento se torna radical em algumas formas textuais e, em outras, pode ser apenas pressentido. Em ambos os casos, implica uma ideia de literatura como jogo irredutível a tarefas pedagógicas, alheio a quaisquer ideais humanitários, políticos ou ideológicos. O escritor é apresentado como alguém que vive em "discontinua contemporaneità con se medesimo". ${ }^{2} \mathrm{O}$ específico da literatura é a linguagem que se estrutura no texto e não na história, entendida como narração de eventos ou como o conjunto das contingências que cercam a produção da obra. Admitem-se apenas referências intertextuais, estabelecendo-se, desse modo, a predileção pelo universo literário.

A peculiaridade da obra de Manganelli se deve ao uso de estratégias de construção textual pelas quais a narrativa é meticulosamente eludida e seu lugar ocupado por dispersões narrativas. Com o conceito de dispersão narrativa, designamos concisamente os diversos gêneros manganellianos caracterizados por uma sintaxe em que predominam as aposições de imagens em vez da reflexão ou narração hipotaticamente ordenada. A marcada presença da metalinguagem - e de inúmeras outras estratégias que mais ocultam do que revelam seu objeto - faz, desses livros, mecanismos para reter o leitor nas dobras do próprio texto e retardar, senão impedir, a criação de eventuais conexões extrínsecas.

Na mesma medida em que, comumente, os textos manganellianos são um discurso sobre a impossibilidade da narrativa, é postulada como igualmente impossível qualquer realidade que se pretenda paradigmática e independente dos jogos linguísticos que a constituem. Negando a precedência das coisas sobre as palavras, faz-se uma clara opção pelo fronteiriço, pelo

2 "Discontínua contemporaneidade consigo mesmo." MANGANELLI. La letteratura come menzogna, p. 220. (Tradução minha) 
estado intermediário, por aquilo que não tem estatuto pragmático de verdade ou de realidade. A idiossincrasia da metafísica manganelliana se deve ao fato de não fundar-se sobre o ato de ser, mas sobre os possíveis do ser. O real passa a ser considerado como essencialmente múltiplo, instável e impossível de ser contido nos estreitos limites dentro dos quais a racionalidade pode funcionar. Isso explica o predomínio de figuras como o oxímoro ou a hipérbole, que revelam, por meio do exagero, da reiteração e da repetição em diferença, os múltiplos aspectos de um mesmo fato ou objeto. Esses são os meios adotados para expor as contradições, a inconsistência, a impossibilidade daquilo que, no cotidiano, por razões pragmáticas, é tratado acriticamente como realidade. Daí o caráter eversivo e transgressor de que se reveste a proposta manganelliana da literatura como mentira, como cerimônia e encenação.

A aversão que Manganelli sente pela expectativa ingênua de ver o "mundo" linearmente transposto para o texto não é uma condenação intransigente a qualquer referencialidade, mas ao simplismo aí implicado: nem o texto, como agenciamento de linguagem, detém os meios necessários para repetir o real e tampouco o real é algo estável e fixo para ser plenamente apreendido. Não há, no objeto, uma inteireza imune à ação do sujeito. A linguagem não é capaz de transparecer nenhuma verdade sem reduzi-la aos seus estreitos limites binários. Por fim, tampouco o leitor possui a faculdade de decodificar um objeto sem submetêlo aos condicionamentos de sua própria percepção e interpretação. Veem-se problematizadas, desse modo, as bases metafísica, linguística e gnoseológica da produção e recepção dos textos literários. Ao invés da alegada solidez desse tripé, é em noções de ser, de linguagem e de conhecimento desestabilizados, que Manganelli funda sua concepção de literatura.

Embora fosse de se esperar que tal sobrevalorização dos aspectos imanentes levasse a um programa de ars gratia artis, a prática de Manganelli como leitor e crítico literário se afasta de um tratamento autorreferencial. Especialmente os prefácios 
recolhidos em Angosce di stile e a coletânea de resenhas, em Laboriose inezie, parecem evitar abordagens puramente estruturais tanto quanto as puramente formais. Quando faz referências a elementos extrínsecos aos textos que analisa, Manganelli não tem o intuito de revelar a verdade da obra, mas de mostrar leituras possíveis, de tal forma diferentes (e, não raro, divergentes) que não podem ser conduzidas a uma verdadeira pela exclusão de outras, reputadas falsas. Os dados extratextuais aportados nas resenhas e prefácios são rigorosamente agenciados de modo a produzir uma imagem da obra analisada; ao invés de uma descrição supostamente objetiva, oferecem uma reinvenção da obra, mediante a participação cocriativa do leitor. As recensões manganellianas se fundamentam na ideia do "falso em verdade": quanto mais documentado, tanto mais fictício e dependente de manipulação. A isso se deve à ideia de que a crítica é uma espécie de "literatura de segundo grau" - uma ficção (no sentido de invento ou constructo) como, sobre e a partir da literatura.

Não obstante a contradição que se insinua nos próprios termos da expressão seguinte, delineia-se algo que poderia ser considerado uma autorreferencialidade relativa, pois, apesar de toda a atenção dedicada ao "desenho da página", não é apenas a materialidade do texto a base da leitura manganelliana. Sua poética se concentra, sim, sobre o texto, mas na qualidade de uma máquina posta em movimento por autor e leitor. Exercer, atuar, encenar são verbos que expressam melhor esse dinamismo pretendido. $\mathrm{O}$ autor não transpõe a realidade para o texto, mas exerce, encena, realiza uma performance.

$\mathrm{Na}$ mesma medida em que se modifica a ideia de autoria, também a leitura deixa de ser a descoberta de um significado oculto. Desloca-se da busca de um dado pretensamente objetivo, para a especulação sobre possíveis resultados de um jogo em pleno funcionamento, pela ação de autor e texto (no momento da

${ }^{3}$ MANGANELLI. Il rumore sottile della prosa, p. 138. 
produção), e de leitor e texto (na recepção). Confrontadas com tal maquinação literária, tornam-se menos desconcertantes a afirmação do autor como uma hipótese desnecessária e a ideia do livro como objeto inexistente. O texto se torna uma cerimônia, um artifício. O espaço literário se torna um campo no qual atuam leitor e autor: "chiunque dica alcunché, in realtà è costretto a recitare la parte di colui che dice, e poco monta che dica, giacché ciò che conta è la parte". “ Não é o argumento apresentado em um texto que está em questão, mas o acontecimento da leitura. Por essa razão, Manganelli ridiculariza a leitura de "segundo grau", expressão com que ele designa a expectativa daqueles leitores, que, sem ter lido um livro, esperam apropriar-se dele por meio de recensões:

Io sono il testo. (...) Questa proposizione è assolutamente centrale, e la letteratura non è altro che l'arte di rendersi consapevoli della inesistenza del libro, in quanto oggetto leggibile. La differenza tra il lettore di primo e di secondo grado è dunque questa: che il secondo crede nell'esistenza del libro, e crede che il libro sia abbastanza sodo da sopravvivere ad una lettura, e addirittura - ma questa si che è grossa - che si possa dire di che cosa parla; un tale delirio non consente speranza di salvezza, e infatti il lettore di secondo grado non incarica qualcuno di leggere operazione priva di senso, come è chiaro - ma lo incarica di tener fermo un libro mentre lui lo uccide. ${ }^{5}$

\footnotetext{
4 "Quem quer que diga alguma coisa, na realidade, é impelido a recitar a parte daquele que diz; e pouco importa o que diz, já que o que conta é a parte." MANGANELLI. Il rumore sottile della prosa, p. 16. (Tradução minha)

5 "Eu sou o texto. (...) Essa proposição é absolutamente central, e a literatura não é outra coisa senão a arte de tornar-se consciente da inexistência do livro enquanto objeto legível. A diferença entre o leitor de primeiro grau e o de segundo é, portanto, esta: que o segundo crê na existência do livro, e crê que o livro seja suficientemente sólido para sobreviver a uma leitura, e até mesmo
} 
O texto é, portanto, um objeto em contínuo devir e que se constitui pela ação do leitor. Parece bastante produtivo aproximar, dessa concepção manganelliana, a teoria da recepção literária, considerando, em particular, as contribuições de Wolfgang Iser e de Karlheinz Stierle. Não obstante o fato de ser cronologicamente posterior às formulações iserianas e de delas depender conceitualmente, a reflexão de Stierle é apresentada, aqui, em primeiro lugar. Tal inversão é motivada pela importância da teoria da ação - implicada na formulação teórica de Stierle e pressuposta tacitamente por Iser $^{6}$ - para a compreensão do papel que o referente ocupa no jogo manganelliano.

Da teoria iseriana do efeito estético à sua "antropologia literária”, mostra-se uma significativa transformação na maneira como é entendida a relação entre leitor e texto. Em nossa leitura da obra manganelliana, torna-se relevante essa passagem de um modelo ainda centrado no texto para um outro que atribui maior importância à propensão do leitor ao indeterminado. Como desdobramento dessa incursão teórica, põem-se em evidência os papéis que, segundo Manganelli, devem ser desempenhados por autor e leitor na constituição do texto literário.

- mas esta sim que é das grandes - que se possa dizer de que é que o livro fala. Um tal delírio não consente esperança de salvação e, de fato, o leitor de segundo grau não encarrega alguém de ler - operação privada de sentido, como está claro - mas o encarrega de segurar um livro enquanto ele o mata." MANGANELLI. Discorso dell'ombra e dello stemma o del lettore e dello scrittore considerati come dementi, p. 117. (Tradução minha)

${ }^{6} \mathrm{O}$ vínculo entre leitura e ação é a base para a formulação da teoria iseriana do efeito estético (cf. ISER. O ato da leitura; uma teoria do efeito estético), mas, embora pressuposta, é tematizada menos explicitamente na obra posterior de Iser (cf. ISER. Ofictício e o imaginário; perspectivas de uma antropologia literária), que interessa mais de perto à concepção de leitura que discutimos aqui. 


\section{DA ONTOLOGIA À PRAGMÁTICA}

Propondo um maior reconhecimento à ação do leitor, a estética da recepção se opõe a perspectivas que consideram o texto apenas em sua imanência. Por outro lado, pretende evitar também uma estética da representação que considera como legítima literatura apenas a que se oferece como reflexo das condições em meio às quais um dado texto surge. ${ }^{7}$ Uma das principais contribuições de Stierle, nesse debate, foi ter elaborado uma "teoria formal da recepção" a partir da tradição fenomenológica husserliana, dos jogos wittgensteinianos de linguagem e da dinâmica da leitura como preenchimento dos vazios do texto, de Wolfgang Iser. Tal teoria encontra um ponto de convergência com a metafísica negativa manganelliana no fato de que Stierle considera a recepção como constituição e não como processamento do texto ficcional. Com isso, Stierle e Manganelli remetem a questão para o âmbito da teoria do conhecimento, ao invés de a encerrarem nos limites das abordagens psicológicas, sociológicas e crítico-ideológicas, ou mesmo da análise de estruturas textuais.

Stierle (2002) parte dos textos pragmáticos, que são aqueles cujos passos recepcionais visam a constituir estados de fato: do mesmo modo que o senso comum supõe uma indiscutível materialidade dos fatos linearmente apreendida pelo pensamento, o leitor busca uma unívoca transposição do real, um significante passível de ser traduzido em um (único) significado. Pela correlação a um contexto que se supõe ser aquele justo, a recepção pragmática reduz a uma ideia mínima o horizonte de possibilidades que gravita em torno de cada frase. Isso leva Stierle a afirmar que, na forma pragmática, o significado resulta de uma hipótese que é projetada sobre a "base material dos significantes". ${ }^{8}$

\footnotetext{
${ }^{7}$ Cf. COSTA LIMA. A literatura e o leitor; textos de estética da recepção, p. 12-14.

${ }^{8}$ STIERLE. Que significa a recepção dos textos ficcionais?, p. 123.
} 
Desde já, é possível perceber uma proximidade entre a teoria de Stierle e a concepção literária de Manganelli. Um e outro constatam que, para produzir sentido, um texto pressupõe uma recepção que não pode, de modo algum, ser considerada uma ação translúcida, como se o texto fosse um dado pronto, acabado e integralmente transmitido. O leitor não é um mero recipiente, vazio e disponível; não recebe passivamente, mas constitui ou, pelo menos, reconstitui por conjecturas o que lê. Como processo que reduz e inventa correlações que se legitimam pela projeção sobre um horizonte de significação precedente ao jogo da leitura, a ação do leitor é compreendida como um falseamento. Na obra de Manganelli, tal modo de ver se combina com a constatação da irredutível polissemia do real. Essa é a base para a afirmação da impossibilidade radical da experiência objetiva e da comunicação a não ser como "mentira". Stierle parece concordar com esse ponto de vista, mas, distintamente, é a pragmática, e não a ontologia, o problema que lhe interessa. Partindo da recepção automatizada, que ele identifica como característica dos "contextos cotidianos da ação verbal", 9 evidencia-se a especificidade da recepção literária, indissociada, porém, de outros tipos de texto. Evita-se, assim, a hipostasia da literatura como uma esfera privilegiada, e a compreensão do texto literário passa a ser projetada sobre o horizonte mais amplo da teoria da ação.

Stierle faz notar que o processo de constituição de um significado a partir da orientação verbal, na recepção pragmática, remete a atenção do leitor para fora do texto e prevê a "adjudicação de uma ação verbal". ${ }^{10}$ Isso significa que o texto deve ser percebido como um conjunto de disposições acionais cuja finalidade reside na resposta pragmática que dele se espera. Produtor e receptor devem, pois, participar de um mesmo esquema de ação e ter em comum um mesmo horizonte de expectativas. O texto pragmático

\footnotetext{
${ }^{9}$ STIERLE. Que significa a recepção dos textos ficcionais?, p. 123.

${ }^{10}$ STIERLE. Que significa a recepção dos textos ficcionais?, p. 126.
} 
se torna centrífugo, pois se exaure no próprio ato de sua tradução em uma determinação situacional.

Embora possua uma forte relação com a forma pragmática, para Stierle o texto ficcional se distingue pelo fato de não se esgotar em uma "simples função de uma realidade a ser retratada", por maior que seja sua vinculação a um conjunto de contingências. Trata-se, antes, de uma "poética da ficção, que pode ser ora mais, ora menos relacionada com a realidade e com a experiência coletiva da realidade". ${ }^{11} \mathrm{O}$ texto ficcional prevê a possibilidade do desvio, pois nele não existe um compromisso de que o estado de fato seja sempre o equivalente ficcional de uma materialidade dos fatos:

A ficção não se deixa corrigir por meio de um conhecimento minucioso da materialidade dos fatos a que se refere. Ao passo que os textos assertivos podem ser corrigidos pela realidade, os textos ficcionais são, no sentido próprio, textos de ficção apenas quando se possa contar com a possibilidade de um desvio do dado, desvio na verdade não sujeito a correção, mas apenas interpretável ou criticável. ${ }^{12}$

É a peculiaridade dessa situação comunicacional que, segundo Stierle, caracteriza efetivamente a ficção. Frente ao texto ficcional, autor e leitor exercem "papéis pragmáticos fingidos", ${ }^{13}$ como se fossem independentes das determinações de suas histórias pessoais. A isso se acrescenta, ainda, que o texto ficcional requer uma indagação sobre o estatuto da própria ficção, de modo que é necessário que o leitor tenha consciência das regras em ação no jogo. É por não suprir tais exigências que, nem sempre, o leitor consegue diferenciar os textos pragmáticos e os ficcionais.

\footnotetext{
${ }^{11}$ STIERLE. Que significa a recepção dos textos ficcionais?, p. 131-132.

${ }^{12}$ STIERLE. Que significa a recepção dos textos ficcionais?, p. 132

${ }^{13}$ STIERLE. Que significa a recepção dos textos ficcionais?, p. 132.
} 
Stierle descreve a situação em que o texto ficcional é recebido como se estivesse submetido às mesmas condições do texto pragmático. Nessa forma de recepção, a "ilusão extratextual" criada pelo texto é interpretada como uma disposição acional. Isso pode resultar apenas da incapacidade do leitor para aperceber-se da especificidade do jogo literário; no entanto, há formas de ficção que contam apenas com essa "recepção quase pragmática", como ocorre na literatura de consumo. São textos que provocam o leitor para a criação de uma realidade ilusória, produzida por uma sucessão de estereótipos e pelo ocultamento do fato de que são apenas mecanismos de linguagem postos em movimento. $\mathrm{O}$ mundo ilusório extratextual ganha consistência pelas disposições internas do texto, que não são intencionadas a problematizar os lugares-comuns da experiência do leitor. A recepção competente da literatura exige, ao contrário disso, a consciência das múltiplas atividades envolvidas no ato de leitura, inatingíveis por uma prática reducionista. No movimento centrífugo da recepção quase pragmática, perde-se aquilo mesmo que constitui a especificidade do texto ficcional.

Sob diversos aspectos, é patente a identidade entre a teoria de Stierle e a reflexão de Manganelli, como o fato de atribuírem à literatura a orientação para a ficcionalidade do próprio texto. Num primeiro momento, Manganelli se distingue pela abordagem radical das possíveis formas de relação com o texto ou pelo tom programático de seu discurso que - poder-se-ia mesmo dizer chega às barras do panfletário, contido apenas pela densidade de sua formulação teórica. No entanto, ele se destaca, em seguida, pelo fato de transformar essas mesmas questões em um projeto literário destinado a driblar quaisquer tentativas de leitura quase pragmática. Trata-se de um projeto que chama a atenção pela explicitação e contínua problematização da performance dos jogadores, das regras pactuadas ou tácitas e da possibilidade de qualquer discurso pôr-se à margem do jogo da linguagem. 
O estranhamento provocado pelos textos manganellianos requer do leitor uma recepção reflexiva, capaz de perceber as rupturas pelas quais os esquemas cotidianamente postos em ação na construção de significados são desautomatizados e desorganizados. São textos que pressupõem a abertura do leitor para surpreenderse com a estranheza da sintaxe e para aceitar o estado de suspensão semântica criado pelas inovações formais que dificultam, tanto quanto possibilitam, a recondução do texto lido a um estado de fato. Os textos de Manganelli poderiam ser considerados como formas textuais que "bloqueia[m] a possibilidade da recepção quase pragmática". ${ }^{14}$ De fato, Stierle afirma que, assim como certos textos preveem apenas tal forma de recepção, existem outros que se inscrevem em uma tradição - em cujo vértice se encontra a obra de Mallarmé - que tem como traço fundamental a autorreflexividade. A dificuldade do texto impede que a ficção se dissolva na ilusão extratextual, e funciona como um impulso para a reflexão sobre a própria linguagem.

Um dos traços que permitem considerar a obra de Manganelli como autorreflexiva é a quase onipresente metalinguagem. Como diz Stierle, a propósito desse tipo de texto, as dispersões narrativas manganellianas parecem sempre visar ao "esclarecimento das condições de uso de seus termos". ${ }^{15}$ Desde Hilarotragoedia, há uma iteração metalinguística levada, posteriormente, ao paroxismo em Nuovo commento. Dentre as obras posteriores de Manganelli, o Discorso dell'ombra e dello stemma o del lettore e dello scrittore considerati come dementi e o Encomio del tiranno: scritto all'unico scopo di fare dei soldi podem ser considerados os momentos de maior evidência dessa característica. Mesmo em outros gêneros, é frequente a tematização da dinâmica operada por autor, leitor e linguagem. O uso reiterado de mecanismos destinados a explicitar tal jogo faz do texto manganelliano uma

\footnotetext{
${ }^{14}$ STIERLE. Que significa a recepção dos textos ficcionais?, p. 154.

${ }^{15}$ STIERLE Que significa a recepção dos textos ficcionais?, p. 138.
} 
espécie de híbrido de narrativa e ensaio, no qual convivem e se interpenetram - regidas pelas regras da metafísica negativa - a imaginação de enredos e a teoria literária, a partir da qual ingressam também a filosofia, a teologia, a psicologia e outros campos do saber.

\section{O ACONTECIMENTO DO TEXTO}

A economia dos textos quase pragmáticos apresentada acima reelabora o princípio da intervenção com que Wolfgang Iser caracteriza a ideia tradicional de interpretação: o texto é reduzido a reflexo unívoco de um dado real, ao qual o leitor pode ligar suas próprias experiências e representações de mundo, esperando descobrir propostas de mudança de vida. Iser e Stierle concordam ao afirmar que essa atitude frente ao texto destrói a experiência literária.

A despeito de uma cronologia que torna implausível a hipótese de recíproca influência, as contribuições de Stierle e de Iser parecem ressoar nas críticas que Manganelli faz às perspectivas naturalizadoras do processo de constituição do sentido em obras literárias. É a desconfiança em relação a uma mentalidade simplista e o interesse comum por compreender o texto como performance que motivam a aproximação entre essas formulações teóricas e a obra de Manganelli.

Também a crítica à noção tradicional de representação é um importante ponto de convergência do pensamento de Manganelli e da estética da recepção. Ambas as abordagens implicam, na ideia de mimese, a referência a uma realidade suposta como passível de ser inequivocamente conhecida e representada. Tal fundacionismo se baseia em um dado que se presume ser precedente ao texto; o autor como alguém que representa esse dado por meio do código linguístico; e o leitor como aquele a quem cabe a tarefa da decodificação. Pouca mobilidade é prevista na definição dessas posições que revelam a centralidade do objeto texto apenas como signo do real nele representado. Na contramão desse imobilismo, a obra de Manganelli pensa o texto como um acontecimento e não 
um estado. Como também afirma Iser, autor, texto e leitor são "intimamente interconectados em uma relação a ser concebida como um processo em andamento". ${ }^{16}$ Em tal performance, o que é referido no texto não predetermina imediatamente o resultado, mas se constitui como o material a partir do qual algo novo se modela.

Já numa primeira fase de sua reflexão, Iser (1996a) se propõe a abandonar o argumento ontológico presente nas teorias que definem a ficção por sua oposição ao real. Essa polarização ocorre também nos discursos que consideram a ficção como autônoma ou como heterônoma, e implica o tratamento da ficção e da realidade como uma "relação entre seres". Para Iser, é necessário substituir tal "argumento ontológico por um funcional" que permita compreender a "estrutura comunicativa", que, em lugar da simples oposição com o real, visa ao funcionamento e aos efeitos da ficção:

Como estrutura comunicativa, a ficção conecta à realidade um sujeito que, por meio da ficção, se relaciona a uma realidade. (...) Se a ficção não é realidade não é porque careça de atributos reais, mas sim porque é capaz de organizar a realidade de tal modo que esta se torna comunicável; por isso, a ficção não se confunde com aquilo que ela organiza. ${ }^{17}$

São lançadas, nesse texto citado, as bases para a noção de transgressão de fronteiras, ${ }^{18}$ que a antropologia literária iseriana introduz. Não se trata de dizer o que é a ficção, mas sim de perceber como ela opera a mediação entre o real e o imaginário. Contudo, nesse primeiro momento de sua reflexão, Iser supõe que o dinamismo da relação entre texto e leitor "funciona de acordo com

\footnotetext{
${ }^{16}$ ISER. O jogo do texto, p. 105.

${ }^{17}$ ISER. $O$ ato da leitura; uma teoria do efeito estético, v. 1, p. 102.

${ }^{18}$ Para uma correlação entre o conceito iseriano de "transgressão de fronteiras" e a concepção literária manganelliana. Cf. ALVES. Antinarratividade e metafísica negativa na obra crítica e literária de Giorgio Manganelli, p. 114-144.
} 
o modelo de sistemas autorreguladores". ${ }^{19}$ Isso implica que "a comunicação com o texto se realiza pela autocorreção latente dos significados construídos pelo leitor". Seguindo essa linha de raciocínio, Iser elabora a sua teoria da leitura como preenchimento dos vazios do texto, segundo a qual, na criação operada pela leitura, o texto desempenha um papel regulador. Por mais que Iser afirme que o leitor "insere no processo da leitura as informações sobre os efeitos nele provocados", ${ }^{20}$ e que a leitura é um processo que "se atualiza por meio dos significados que o próprio leitor produz e modifica", ainda assim conserva-se o entendimento de que a ação do leitor acontece nas brechas do texto e, portanto, apenas nos limites já previstos pelo próprio texto. Com isso, reintroduz-se a precedência do texto ao jogo da leitura. É significativo que, nessa formulação, Iser afirme a existência de textos literários que permitem graus diferenciados de intervenção imaginativa: diminuindo o "número de lugares vazios (...), perde intensidade também a formação de representações do leitor estimulada por essas lacunas". ${ }^{21}$ Não obstante a forma relacional e processual com que é compreendido, o ato da leitura assim concebido continua centrado no objeto texto.

Num segundo momento da obra de Iser, essa presença do texto é relativizada por uma abordagem da obra literária e da leitura segundo o princípio de indeterminação. De acordo com tal princípio, o efeito estético se operacionaliza não pelo preenchimento dos vazios do texto, mas pela imaginarização, ou seja, por um processo de indeterminação do estado de fato constituído pelo texto. A ação do leitor não se reduz a uma intervenção já prevista por uma estrutura lacunar. Qualquer texto pode adquirir múltiplas determinações semânticas ao ser agenciado pelo leitor de maneiras potencialmente infinitas. Daí o caráter transgressivo da leitura.

\footnotetext{
${ }^{19}$ ISER. $O$ ato da leitura; uma teoria do efeito estético, v. 1, p. 126.

${ }^{20}$ ISER. $O$ ato da leitura; uma teoria do efeito estético, v. 1, p. 127.

${ }^{21}$ ISER. $O$ ato da leitura; uma teoria do efeito estético, v. 1, p. 137.
} 
Ao explicar a leitura como uma indeterminação do texto operada pelo leitor, Iser parte da afirmação aristotélica de que a representação tem por função "completar o que a natureza deixara incompleto". ${ }^{22}$ Deduz-se, a partir disso, que a mimese não pode ser restrita à "mera imitação do que é, pois os processos de elucidação e de complementação exigem uma atividade perfomativa" para que "ausências aparentes" se transformem em presença. A representação como mímesis, afirma Iser, é devida a sistemas fechados, como as cosmovisões grega e medieval, que consideravam que "todo o existente - mesmo que se esquivasse à percepção-deveria ser traduzido em algo tangível". Ao contrário disso, a performance "não mais implica vir aquém das aparências para captar um mundo inteligível, no sentido platônico, mas se converte em um 'modo de criação de mundo'". ${ }^{23}$

Nesse sentido, a única representação possível é aquela que tem como "objeto referencial" os próprios "modos de criação de mundo" e, assim, o "componente performativo teria de ser concebido como o pré-dado do ato performativo". ${ }^{24}$ Essa formulação parece estar implicada na noção de autorreflexividade de que Stierle se serve, como citado anteriormente, para tratar dos textos que visam ao "esclarecimento das condições de uso" 25 de seus próprios termos. Trata-se de uma perspectiva que ajuda a compreender por que a literatura de Manganelli é quase sempre metalinguística. Efetivamente, seus textos explicitam e tematizam os procedimentos literários e, ainda que de maneira ironicamente invertida, realizam, no ato da enunciação, aquilo mesmo que enunciam. Ao invés da expectativa de encontrar elementos extratextuais representados no texto, isso implica concebê-los como parte do processo; em

\footnotetext{
${ }^{22}$ ISER. O jogo do texto, p. 105.

${ }^{23}$ ISER. O jogo do texto, p. 105-106.

${ }^{24}$ ISER. O jogo do texto , p. 106.

${ }^{25}$ STIERLE. Que significa a recepção dos textos ficcionais?, p. 138.
} 
termos iserianos, são "componentes materiais do que sucede no texto e não representados um a um". ${ }^{26}$

A proposta de Iser é substituir a ideia de representação pela noção de jogo à qual ele atribui a capacidade de "abarcar a operação performativa do texto como uma forma de evento". ${ }^{27}$ Para Iser, o conceito de jogo possui, sobre a ideia de representação, a vantagem heurística de não se ocupar dos possíveis significados e de não ter de "retratar nada fora de si próprio". A literatura implica o movimento e a interação entre autor-texto-leitor: "os autores jogam com os leitores e o texto é o campo do jogo". ${ }^{28}$ Qualquer tentativa de formar uma definição dos elementos desse jogo recoloca a relação triádica, sem predomínio ou prevalêcia de qualquer um deles. Assim, pode-se dizer que o texto resulta de um "ato intencional pelo qual um autor se refere e intervém em um mundo existente", ${ }^{29}$ o qual só poderá tornar-se acessível à consciência se for transgredido e modificado pela dupla operação de imaginar e interpretar, levada a termo pelo leitor.

O texto ficcional se caracteriza como uma encenação. Iser fala da "convenção de um contrato entre autor e leitor" em razão do qual o mundo textual é "concebido não como realidade, mas como se fosse realidade" ${ }^{30} \mathrm{O}$ mundo repetido no texto é diferente daquele a que se refere, pois "nenhuma descrição pode ser aquilo que descreve". Sabe-se, de partida, que essa diferença não pode ser eliminada, mas ao construir pontes de sentido, o leitor procede por conjecturas, acionando, desse modo, o jogo.

O objetivo desse jogo textual não é atingir o significado do texto ao qual o leitor não pode chegar senão pela tomada de

\footnotetext{
${ }^{26}$ ISER. O jogo do texto, p. 106.

${ }^{27}$ ISER. O jogo do texto, p. 106.

${ }^{28}$ ISER. O jogo do texto, p. 107.

${ }^{29}$ ISER. O jogo do texto, p. 107.

${ }^{30}$ ISER. O jogo do texto, p. 107.
} 
decisões com relação a aspectos indecidíveis. Os jogos visam resultados, mas qualquer resultado é redutor, pois implica a suspensão do movimento. A diferença tende a ser preservada tanto quanto se procura erradicá-la. Devido a essa dualidade, "o jogo do texto só pode ser avaliado em termos de suas possibilidades, por meio das estratégias empregadas no jogo, e pelos jogos de fato realizados no texto". ${ }^{31} \mathrm{Em}$ razão disso, Iser afirma que o significado do texto é uma espécie de suplemento - ato pelo qual o leitor converte a ausência em presença - não preexistente ao jogo. A ideia de suplemento "admite diferentes desempenhos por diferentes leitores no ato de recepção". ${ }^{32}$ Isso a distingue da noção de complemento, a qual pressupõe que o processo de atribuição de sentido funcione como um quebra-cabeças em que uma lacuna pode ser preenchida por uma única peça.

Iser se serve de uma noção formulada por Jacques Derrida, segundo a qual o suplemento é "aquilo que parece acrescentarse como um pleno a um pleno", ${ }^{33}$ suprindo uma falta existente já na origem. Isso implica compreender, de maneira contraditória, a ação do leitor como uma adição que completa ou compensa uma lacuna no que, em si mesmo, já é completo: "o texto que se denomina presente só se decifra no pé da página, na nota ou postscriptum. Antes desta recorrência, o presente não passa de um apelo de nota". ${ }^{34}$ Assim, o texto não é "originário", mas "reconstituído". A leitura, entendida como um ato de suplementação, deixa de ser algo que pode ser contido e descrito por contraposição ao texto. Dissolvem-se os polos de texto e leitor, significante e significado, representante e representado. Como afirma Derrida, esses termos e oposições se enraizam irredutivelmente na metafísica e não podem dominar a "economia da suplementaridade":

\footnotetext{
${ }^{31}$ ISER. O jogo do texto, p. 109.

${ }^{32}$ ISER. O jogo do texto, p. 108,

${ }^{33}$ DERRIDA. A escritura e a diferença, p. 200.

${ }^{34}$ DERRIDA. A escritura e a diferença, p. 200.
} 
"o suplemento não é nem uma presença nem uma ausência. Nenhuma ontologia pode pensar a sua operação". ${ }^{35}$

\section{SENTIDO E INDETERMINAÇÃO}

Os aspectos aqui discutidos colaboram na compreensão da maneira como Manganelli associa semântica e indeterminação. Para ele, em torno de uma palavra forma-se um halo de significações, entre as quais o significado pragmaticamente atribuído constitui apenas uma possibilidade entre outras. De modo semelhante, Iser ${ }^{36}$ percebe um jogo entre o uso figurativo e o denotativo que se expressa por meio do "significante fraturado". Ao mesmo tempo que algo é denotado, nega-se tal uso, sem que seja abandonado aquilo que se designa na primeira instância. $\mathrm{O}$ significante funciona como um "análogo para a figuração de algo mais”. Algo ausente é presentificado: o significante fraturado "invoca alguma coisa que não é pré-dada" mas engendrada por ele, que habilita o leitor a dotá-lo de uma forma tangível”. Não é mais o significado do texto que está em questão, mas a ativação do imaginário pelo leitor.

Requerendo essa ação do leitor, os textos de Manganelli levam a indeterminação ao paroxismo. Não importa, propriamente, o assunto de que trata um texto, mas sim que este cumpra a função de provocar o leitor para ocupar seu lugar na geração de imagens e na produção de sentidos. Na teoria manganelliana da leitura, conclui-se o arco cujo traçado parte da metafísica negativa. Por serem autorreflexivos, seus textos se concentram na proposição de valores e normas com a exclusiva finalidade de confrontá-los com outros, de sinal contrário. Mesmo suas narrativas se caracterizam pela apresentação de ideias em franca rota de colisão, conflitos

\footnotetext{
${ }^{35}$ DERRIDA. Gramatologia, p. 383-385.

${ }^{36}$ ISER. O jogo do texto, p. 110.
} 
que o leitor não pode resolver senão por uma decisão arbitrária que o levaria a determinar um significado. Isso, porém, é sistematicamente inviabilizado por estratégias de construção textual que minam grande parte dos elementos que poderiam subsidiar tal decisão: as informações que restam como material para a construção de conjecturas são, frequentemente, subvertidas, carnavalizadas e dispostas, no texto, umas contra as outras. Como máquina de produção de imagens, o texto manganelliano tende a funcionar como um desenho, um jogo de sombras e figuras obliteradas.

Pode-se destacar o Encomio del tiranno como uma das dispersões manganellianas em que essas questões aparecem mais explicitamente formuladas. Trata-se de um discurso dispersivo e iterativo, uma típica antinarrativa: "pian piano, chiacchierando, sbadigliando, sussurrando, proclamando, argomentando, insinuando, si procede di capitolo in capitolo" ${ }^{37}$ É um discurso em primeira pessoa, como uma carta do escritor ao editor, ao mesmo tempo que é uma reflexão sobre a literatura e os papéis de leitor e autor. Constituise como uma contraposição de pares de conceitos-personagens: editor e escritor, monarca e bobo da corte, tirano e bufão. A peculiaridade desse livro reside, porém, na confusão e paulatina dissolução das identidades iniciais. Mostra-se a insuperável interdependência de cada polo das relações. Cria-se uma zona de indefinição na qual já não se podem distinguir dois personagens, mas, de cada um, apenas aquilo que permite falar sobre o outro:

Dovrei dire che la tirannia è contenuta nella buffoneria come questa in quella; insomma che v'è una così fatta complicità che non c'è da stupirsi se tanti tratti dell'una sono reperibili nell'altra, sebbene

\footnotetext{
37 "Pouco a pouco, tagarelando, bocejando, sussurrando, proclamando, argumentando, insinuando, avança de capítulo em capítulo." MANGANELLI. Encomio del tiranno; scritto all'unico scopo di fare dei soldi, p. 12. (Tradução minha)
} 
sia ovviamente impossibile distinguere in che modo certi tratti siano propri dell'una o dell'altra; e sebbene nessuno abbia dubbio o perplessità a distinguere l'una dall'altra. ${ }^{38}$

A imagem do leitor como tirano e do escritor como bufão mostra o texto como um jogo em que as posições devem ser transgredidas para se pôr em movimento. A bufonaria do escritor consiste em ser ele um "gestore di una macchinazione mista di scherzi e orrori"; 39 a tirania do leitor é o exercício de seu poder "veramente assoluto e tale che nessuno possa né sfidarlo né giudicarlo". ${ }^{40}$ São, porém, papéis complementares e intercambiáveis que se realizam apenas no ato da leitura.

Sintesi: Nell'opera dello scrittore italiano Giorgio Manganelli, l'autore, il lettore e addirittura il proprio testo si deontologizzano e diventano componenti di una performance, ruoli pragmatici che fanno della letteratura un gioco di produzione di sensi contingenti. Privilegiando la lettura di un genere testuale manganelliano qui designato come dispersione narrativa, questa peculiare teoria della letteratura viene analizzata alla luce della teoria formale della ricezione, di Karlheinz Stierle, e dell'antropologia letteraria, di Wolfgang Iser.

38 "Deveria dizer que a tirania está contida na bufonaria, como esta naquela; em suma, que há uma tal cumplicidade que não é de se espantar que tantos traços de uma possam ser encontrados na outra, se bem que seja obviamente impossível distinguir em que modo certos traços sejam próprios de uma ou de outra; e se bem que ninguém tenha dúvida ou perplexidade ao distinguir uma da outra." MANGANELLI. Encomio del tiranno; scritto all'unico scopo di fare dei soldi, p. 29. (Tradução minha)

39 “(...) gestor de uma maquinação mista de brincadeiras e horrores.” MANGANELLI. Encomio del tiranno; scritto all'unico scopo di fare dei soldi, p. 29. (Tradução minha)

40 “(...) verdadeiramente absoluto e tal que ninguém possa nem desafiá-lo nem julgá-lo." MANGANELLI. Encomio del tiranno; scritto all'unico scopo di fare dei soldi, p. 29. (Tradução minha) 


\section{REFERÊNCIAS}

ALVES, C. F. Antinarratividade e metafísica negativa na obra crítica e literária de Giorgio Manganelli. Belo Horizonte: Faculdade de Letras - UFMG, 2008. (Tese de Doutorado)

COSTA LIMA, L. A literatura e o leitor; textos de estética da recepção. 2. ed. rev. ampl. Rio de Janeiro: Paz e Terra, 2002.

DERRIDA, J. A escritura e a diferença. 2. ed. São Paulo: Perspectiva, 1995.

DERRIDA, J. Gramatologia. 2. ed. São Paulo: Perspectiva, 1999.

ISER, W. O ato da leitura; uma teoria do efeito estético. São Paulo: Ed. 34, 1996a. $2 \mathrm{v}$.

ISER, W. O fictício e o imaginário; perspectivas de uma antropologia literária. Rio de Janeiro: EdUERJ, 1996b.

ISER, W. O jogo do texto. In: COSTA LIMA, L. A literatura e o leitor; textos de estética da recepção. 2. ed. rev. ampl. Rio de Janeiro: Paz e Terra, 2002.

MANGANELLI, G. Angosce di stile. Milano: Rizzoli, 1981.

MANGANELLI, G. Discorso dell'ombra e dello stemma o del lettore e dello scrittore considerati come dementi. Milano: Rizzole, 1982.

MANGANELLI, G. Pinocchio: un libro paralelo. Torino: Einaudi, 1982a. (Trad. brasileira por Eduardo Brandão. São Paulo: Companhia das Letras, 2002.)

MANGANELLI, G. La letteratura come menzogna. 2. ed. Milano: Adelphi, 1985.

MANGANELLI, G. Laboriose inezie. Milano: Garzanti, 1986.

MANGANELLI, G. Encomio del tiranno; scritto all'unico scopo di fare dei soldi. Milano: Adelphi, 1990.

MANGANELLI, G. Nuovo commento. Milano: Adelphi, 1993.

MANGANELLI, G. Il rumore sottile della prosa. Milano: Adelphi, 1994.

MANGANELLI, G. Centuria; cento piccoli romanzi fiume. 2. ed. Milano: Adelphi, 1998. (Trad. brasileira por Roberta Barni: Centúria; cem pequenos romances-rio. São Paulo: Iluminuras, 1995.) 
MANGANELLI, G. Hilarotragoedia. 3. ed. Milano: Adelphi, 2001. (Trad. brasileira por Nilson Moulin. Rio de Janeiro: Imago, 1993.)

MANGANELLI, G. La letteratura come menzogna. 2. ed. Milano: Adelphi, 2004.

STIERLE, K. Que significa a recepção dos textos ficcionais? In: COSTA LIMA, L. A literatura e o leitor; textos de estética da recepção. 2. ed. rev. ampl. Rio de Janeiro: Paz e Terra, 2002. p.119-171. 